\title{
Modelagem Matemática e Educação Financeira: uma integração possível no desenvolvimento da criticidade dos estudantes
}

\author{
Mathematical Modeling and Financial Education: a possible integration in the \\ development of students' criticality
}

\author{
Gabriela dos Santos Barbosa \\ Jerlan Manaia de Araújo \\ Ana Marlice Manhães Paes
}

\begin{abstract}
Resumo: O presente artigo tem como foco a modelagem matemática e
no contexto da Educação Financeira num curso pré-vestibular social de Duque de Caxias, Rio de Janeiro. Na pesquisa apresentada, a modelagem consistiu na investigação por meio da Matemática de temas definidos como interessantes pelos estudantes, que estavam divididos em grupos. Para contemplar o objetivo de descrever e analisar o processo de modelagem matemática vivenciado pelos estudantes e suas potencialidades críticas, realizamos uma pesquisaação composta por três atividades de ensino. Os resultados nos levam a concluir que a Educação Financeira oferece circunstâncias para a modelagem que, além de envolver a revisão e construção de conceitos matemáticos, permitem o desenvolvimento de uma postura crítica no que concerne ao consumismo e às desigualdades sociais brasileiras.
\end{abstract}

Palavras-chave: Modelagem Matemática. Estudantes. Educação Financeira.

Abstract: This article focuses on mathematical modeling and problem solving in the context of Financial Education in the pre-university entrance exam course in Duque de Caxias, in Rio de Janeiro. In the research of Results, a modeling consisted of investigation through mathematical themes related to interesting students, who were divided into groups. To contemplate the objective of describing and analyzing the mathematical modeling process experienced by the students and their potential criticisms, we carried out an action research composed of three teaching activities. The results lead to the conclusion that Financial Education offers circuits for modeling, in addition to involving the review and construction of mathematical concepts, the use or development of a critical approach with regard to consumption and social difficulties in Brazil.

Keywords: Mathematical Modeling. Students. Financial Education.

\section{Introdução}

O presente artigo tem como objetivo descrever e analisar o processo de modelagem matemática vivenciado por estudantes de um pré-vestibular social e suas potencialidades para 0
Gabriela dos Santos Barbosa Doutora em Educação Matemática. Professora do Programa de Pós-Graduação em Educação, Cultura e Comunicação da Universidade do Estado do Rio de Janeiro (UERJ). Rio de Janeiro, Brasil.

(iD) orcid.org/0000-0003-4442-6022 $\bowtie$ gabrielasb80@hotmail.com

Jerlan Manaia de Araújo Mestre em Educação, Cultura e Comunicação. Professor da Universidade do Estado do Rio de Janeiro (UERJ). Rio de Janeiro, Brasil.

iD orcid.org/0000-0002-0340-652X $\bowtie$ jerlanmanaia@icloud.com

Ana Marlice Manhães Paes Mestranda em Educação, Cultura e Comunicação pela Universidade do Estado do Rio de Janeiro (UERJ). Rio de Janeiro, Brasil.

iD orcid.org/0000-0002-7904-1459

$\bowtie$ marlicepaes@gmail.com

Recebido em 05/07/2020

Aceito em 16/10/2020 Publicado em 23/11/2020 
desenvolvimento da capacidade crítica deles. Um pré-vestibular social se distingue de outros prévestibulares por não ter fins lucrativos e voltar-se para estudantes pertencentes a famílias de baixa renda. Desse modo, trata-se de uma pesquisa-ação, que pode ser classificada como socialmente crítica (TRIPP, 2005), pois trabalhamos para, num sentido mais amplo, contribuirmos para a justiça social e para a valorização de nossos sujeitos e seus saberes.

A modelagem matemática vem se apresentando como uma tendência em Educação Matemática desde o final do século XX. Ela teve mais destaque como estratégia de ensino e aprendizagem a partir da década de 1980, quando surgiram os primeiros cursos de PósGraduação em Modelagem Matemática. Em 2001 a Sociedade Brasileira de Educação Matemática (SBEM) criou o Grupo de Trabalho (GT) de modelagem matemática, o que alavancou ainda mais as produções nessa área e suas aplicações principalmente no ensino de matemática na educação básica.

Definir o que é a modelagem matemática não tem sido uma tarefa simples. Adotamos nesse estudo a definição de Bassanezi (1994), quando afirma que a modelagem matemática é a arte de transformar problemas da realidade em problemas matemáticos, de modo que sua resolução possa surgir da interpretação de suas soluções na linguagem do mundo real. Consideramos também os resultados da pesquisa de Araújo (2002) sobre as perspectivas da modelagem na Educação Matemática. A autora sinaliza a existência de uma gama de perspectivas entre as quais destaca três: a de Bassanezi (2002), a de Galbraith e Clatworthy (1990) e a de Borba, Meneguetti e Hermini (1997), e reconhece que "as três têm em comum a utilização da Matemática para o estudo de problemas ou situações reais entre os seus objetivos" (ARAÚJO, 2007, p. 24). Influenciados por Borba, Meneguetti e Hermini (1997), reconhecemos a importância de os estudantes escolherem o tema ou problema a ser modelado. A modelagem, assim, está imbricada com resolução de problemas que tenham significado para os estudantes, levando-os a perceber as aplicações dos conceitos e até mesmo da simbologia matemática que estudam. Esse entendimento, por sua vez, destaca a relevância da modelagem como estratégia de ensino e aprendizagem e justifica investimentos em pesquisas científicas na área. Para trazermos um exemplo que corrobora com essa ideia, citamos, ainda, a pesquisa de Andreatta e Allevato (2020). Nela, tendo como sujeitos estudantes do $5^{\circ}$ ano do Ensino Fundamental, as autoras puderam concluir que, ao elaborar problemas, os estudantes desenvolvem aspectos relacionados à criatividade e à criticidade, além de avançarem na compreensão dos significados que subjazem as operações de adição, subtração, multiplicação e divisão. 
No curso pré-vestibular onde um de nós atua como professor de Matemática, devido ao fato de os estudantes serem jovens e adultos pertencentes a famílias de baixa renda, temas que frequentemente despertam 0 interesse dos estudantes são aqueles relacionados a questões financeiras e orçamento doméstico. A pesquisa de Araújo (2020), realizada no mesmo local, voltada para as concepções dos estudantes sobre Educação Financeira, reforçam tal constatação e nos levaram a questionar sobre as potencialidades do contexto da Educação Financeira para a modelagem matemática e, consequentemente, para a aprendizagem de conceitos matemáticos de modo significativo e crítico. Percebemos que atividades de modelagem matemática conduzem os estudantes a pensarem matematicamente e levantamos a hipótese de que, associadas à Educação Financeira, podem contribuir para que os estudantes analisem criticamente a realidade em que estão inseridos. Sendo assim, estabelecemos o objetivo da pesquisa apresentada neste artigo e, para contemplá-lo, realizamos uma intervenção de ensino composta por três atividades que foram colocadas em prática em dois encontros com os estudantes do curso. Essa pesquisa se justifica por contribuir simultaneamente para as discussões acadêmicas sobre aprendizagem de conceitos matemáticos e sobre a inserção da Educação Financeira no currículo da educação básica.

Cabe mencionar ainda que entendemos a Educação Financeira num amplo sentido, que não a restringe apenas a conceitos da Matemática Financeira. Corroboramos com as ideias de Kistemann Jr. (2011) e Kistemann Jr. e Lins (2014), quando afirmam que a Educação Financeira deve permitir que o estudante não só aprenda as melhores maneiras de adquirir um bem, produto ou serviço, mas principalmente reflita sobre se deve ou não adquiri-lo, percebendo o consumismo como um instrumento da ordem capitalista, que legitima a desigualdade social (BAUMAN, 2008). Para facilitarmos a compreensão das nossas ideias e das etapas da pesquisa que realizamos, na próxima seção, apresentamos uma síntese dos pontos de aproximação entre a modelagem e a resolução de problemas. Na sequência, descrevemos as ideias sobre Educação Financeira que nos fundamentam. Por fim, trazemos as informações do campo, descrevemos o método que empregamos na pesquisa, fazemos a análise dos resultados e tecemos nossas considerações finais.

\section{A Educação Matemática, a modelagem e a resolução de problemas}

É consenso, nos resultados de pesquisas em Educação Matemática desenvolvidas nas duas últimas décadas (BARBOSA, 2008; KISTEMANN JR., 2011; NACARATO, MENGALI e 
PASSOS, 2015; ARAÚJO, 2020), a necessidade de se romper com as metodologias tradicionais de ensino nas aulas de Matemática. Para explicar o entendimento sobre a metodologia tradicional, Nacarato, Mengali e Passos (2015) explicam que essa se baseia na resolução de exercícios repetitivos, extraídos de livros didáticos que ocupam um papel central da aula, e que cabe ao professor corrigir os estudantes, sem, contudo, refletir junto a eles sobre seus erros. Percebemos, assim, que, no modelo tradicional, o professor assume a postura de transmissor em vez de produtor de saberes e que o ensino, que privilegia resultados e não conceitos, ocorre de forma totalmente mecanizada, desprovida de significados, com pouca ou nenhuma participação dos estudantes.

Indo de encontro à metodologia tradicional, Gomes (1998) reforça que aprender Matemática é adquirir ferramentas cognitivas para matematizar situações pertencentes a um mundo em constantes avanços. Assim,

\begin{abstract}
faz-se necessário que a Educação Matemática não seja interpretada como sinônimo de ensino de matemática, mas como uma área de conhecimentos, em que o educador e educando se apresentam numa relação de cumplicidade, de parceria de troca; entendida como uma forma de pensamento, como uma "ferramenta" cognitiva, como instrumento para a leitura do mundo e que, muitas vezes, depende de outras áreas do conhecimento, que o processo de aquisição de conhecimentos não implicasse numa relação de dominação, mas numa base constante de novos desafios, com base na pesquisa, na reconstrução e, principalmente, na compreensão. (GOMES, 1998, p.31).
\end{abstract}

Ou seja, a autora sugere que é necessário tratar a Matemática como uma ciência passível de questionamentos e abolir a ideia, que ainda perdura em algumas instituições de ensino, de que ela seja a "ciência da quantidade", cabendo ao estudante apenas aprender a fazer contas e a medir, sem questionar como se dão esses processos e sem analisar de maneira crítica os contextos em que eles se aplicam.

Para reverter esse quadro, Smole, Diniz e Cândido (2000), Smole (2003), Allevato e Onuchic (2009) e Van de Walle (2009) propõem o ensino com base na resolução de problemas desde os anos iniciais da educação básica até a formação de professores. Segundo Smole, Diniz e Cândido (2000),

um dos maiores objetivos para o estudo da Matemática na escola é desenvolver a habilidade de resolver problemas. [...] não só pela sua importância como forma de desenvolver várias habilidades, mas especialmente por possibilitar ao aluno a alegria de vencer obstáculos criados por sua própria curiosidade, vivenciando, assim, o que significa fazer Matemática (p. 13). 
Em consonância com essas autoras, Onuchic (1999 p. 215) destaca que "um problema é tudo aquilo que não se sabe fazer, mas que se está interessado em resolver", e Van de Walle (2009, p. 57) ainda acrescenta que "um problema é qualquer tarefa ou atividade para a qual os estudantes não têm regras ou métodos prescritos ou memorizados, nem há um sentimento por parte dos estudantes de que há um método 'correto' específico de solução".

Desse modo, o estudante é conduzido a explorar as possibilidades propiciadas quando são apresentados problemas matemáticos e a resolução de problemas é vista como uma estratégia de ensino que favorece o envolvimento do estudante para analisar, pensar, vivenciar experiências de ensino onde ele possa encontrar "algo novo" no processo e então, descobrir uma matemática significativa e necessária ao seu aprendizado. É nessa direção, inclusive, que identificamos pontos de aproximação entre os estudos voltados para a resolução de problemas e a modelagem matemática. Entretanto, a modelagem vem acrescentar à resolução de problemas um potencial crítico. Para não se incorrer no risco de se propor aos estudantes "problemas escolares idealizados" (CHEVALLARD, BOSCH e GASCÓN, 2001, p. 10), que, muitas vezes, omitem a problemática e não fazem sentido para os estudantes, a modelagem matemática tal como apresentamos na introdução traz contribuições. Nela, os estudantes participam também do levantamento e elaboração de situações-problema de seus interesses, para, em seguida, desenvolver suas estratégias de resolução. Motivados por problemas que lhes são significativos, em atividades de modelagem, os estudantes têm oportunidade de observar padrões numéricos, integrar conceitos matemáticos que, aparentemente, não possuem pontos de aproximação e aplicam-nos em contextos que consideram relevantes. Resolve-se o problema e, nesse processo, desenvolvem-se habilidades gerais de exploração e o papel sociocultural da matemática é reconhecido (BLUM, 1995).

As práticas que realizamos em nossa pesquisa de campo foram elaboradas sob a luz dessas ideias e tendo como foco a Educação Financeira, cujo interesse foi manifestado por nossos sujeitos, os estudantes do pré-vestibular social. São características dessas práticas, por exemplo, a construção de um ambiente em sala de aula em que o estudante se sinta à vontade para manifestar suas estratégias de resolução, seus modos de ser e viver e suas opiniões. Além disso, o diálogo constante entre os estudantes e entre esses e o professor é também uma marca. Mas, como apropriar para a Educação Financeira os aspectos críticos da modelagem e da resolução de problemas que nos fundamentam? Na próxima seção, tentamos responder tal questão. 


\section{O Contexto da Educação Financeira}

No Brasil e no mundo, o número de famílias endividadas é bem significativo. Segundo dados da Pesquisa de Endividamento e Inadimplência do Consumidor (PEIC), apurada pela Confederação Nacional do Comércio de Bens, Serviços e Turismo (CNC), o percentual de famílias brasileiras com contas ou dívidas em atraso no mês de julho de 2018 foi de 59,6\%. São dívidas com cartão de crédito, cheque especial, empréstimos, financiamento de imóvel, prestação de carro e tantas outras. Contudo, o cartão de crédito foi apontado como o principal tipo de dívida em 76,4\% das famílias endividadas. Souza e Torralvo (2008) asseguram que o fácil acesso ao crédito e a ausência de planejamento financeiro são as justificativas para os elevados índices.

Os dados apurados pela CNC revelam ainda que os resultados são semelhantes entre as diversas faixas de renda. Para as famílias com renda de até dez salários-mínimos, o percentual de endividamento foi de $60,8 \%$, enquanto nas famílias com renda acima de dez salários-mínimos, o percentual é de $54,1 \%$. Isso nos leva a questionar que a falta de planejamento financeiro não está ligada ao poder aquisitivo de um indivíduo, já que os números permanecem altos até mesmo nas faixas de renda mais elevadas. Nessa perspectiva, Saito (2007) ressalta que "o êxito na gestão das finanças pessoais não está relacionado exclusivamente ao nível de recursos financeiros acumulados por um indivíduo durante sua vida, mas à capacidade de planejar a disponibilidade destes, para a realização de projetos pessoais e familiares" (p. 19).

Para entendermos os motivos que levam à ausência de planejamento financeiro, precisamos analisar a estrutura econômica vigente, que é majoritariamente capitalista. O consumo é a peça-chave nesse jogo do mercado, portanto para o sistema permanecer em funcionamento, é necessário o recrutamento de uma sociedade de consumidores, que estejam prontos a consumir o que lhes for apresentado. Bauman (2008) nos apresenta uma característica importante dessa sociedade: "a transformação dos consumidores em mercadorias, ou antes, sua dissolução no mar de mercadorias" (p. 20).

Esse autor destaca também que as pessoas não estão preocupadas apenas consigo mesmas, mas em serem vistas, notadas, comentadas, desejadas etc. Assim, vender-se para a sociedade é o normal, a invisibilidade é o equivalente à morte social e o surgimento das redes sociais corroborou para o aguçamento dessa perspectiva.

Nas últimas décadas houve um crescimento exponencial no acesso às redes sociais, de tal forma que muitas pessoas, especialmente os jovens, estão cada vez mais conectadas. 0 
sucesso foi tão grande que, a todo instante, surgem novas redes sociais. Imersos nessa cibercultura, agora os indivíduos passam a maior parte do tempo acompanhados de um smartphone, computador e tantos outros aparatos tecnológicos. O contato físico com outros indivíduos está ocorrendo com frequência cada vez menor. A vida pessoal que antes era privada, agora é exposta nas redes de forma cada vez mais rápida e eficiente. Podemos perceber que mesmo após o fim da escravidão, a mercantilização da sociedade ainda existe, apenas foi reorganizada de uma forma sutil. Enquanto antes essas relações eram bem nítidas, agora os indivíduos são manipulados ideologicamente de forma que queiram se vender, sem a necessidade do uso de força ou violência física. É válido destacar, ainda, que a manipulação consiste também em levar os indivíduos a adquirir bens duráveis ou não duráveis, sem refletir sobre suas reais necessidades, cedendo apenas aos apelos da mídia ou às inovações do mercado.

De acordo com Bauman (2008), vivemos tempos líquidos, nos quais a velocidade com que as transformações ocorrem aumenta a cada dia. Assim, as relações estão cada vez mais dinâmicas, fluidas e velozes. Ao analisar a produção de mercadorias, podemos perceber que a todo instante surgem novos produtos nas prateleiras e vitrines das lojas.

Kistemann Jr. (2011, p. 71) distingue algumas características marcantes dessa sociedade de consumo, também chamada por ele de sociedade de consumo líquido moderna, que são: "(i) 0 consumo de massas; (ii) a moda em velocidade de progressão geométrica; (iii) mercadorias descartáveis, mercadorias-signo; (iv) sentimento de insaciabilidade, e o principal, (v) o indivíduo consumidor como seu personagem central".

Nesse sentido, a mídia tem um papel muito importante na sociedade de consumidores, pois ela favorece a manutenção e o fortalecimento destas características. Ela permite, por exemplo, criar nos indivíduos desejos pelo consumo, associando consumo à felicidade. Esses desejos são despertados por meio de propagandas, comerciais, outdoors e em diversos veículos de publicidade. Importante observar, no entanto, que nem toda imposição ao consumo é apresentada de forma explícita. A cultura do consumo é fomentada até mesmo pelo simples fato de pessoas famosas utilizarem um determinado produto. $O$ produto usado logo entra na moda e a sociedade passa a desejar adquiri-lo (BAUMAN, 2008; KISTEMANN JR., 2011).

Existem muitas imposições de consumo veladas na sociedade, que são naturalizadas. A compra de uma casa é um exemplo de algo que é exigido pela sociedade, fazendo com que muitas famílias fiquem endividadas e comprometam grande parte de seus rendimentos durante toda a 
vida produtiva. Contudo, em muitos casos, os juros cobrados na compra de um imóvel financiado em muitos anos são altíssimos e, se o dinheiro do financiamento fosse economizado, mesmo descontando-se o valor de um aluguel, o montante acumulado ao final do período possibilitaria a aquisição de vários imóveis do mesmo valor.

Bauman (2008), Kistemann Jr. (2011) e Kistemann Jr. e Lins (2014) destacam ainda que a sociedade de consumo, para se manter, precisa tornar perpétua a não satisfação de seus consumidores, por isso a todo instante surgem novos produtos no mercado. A moda de roupas, por exemplo, está a todo instante sendo alterada. Muitas vezes o indivíduo nem teve oportunidade de vestir e a roupa já saiu de moda. Os celulares, por sua vez, possuem suas tecnologias inseridas nos aparelhos de forma gradativa, a fim de sempre tornar ultrapassado e retrógrado o aparelho lançado anteriormente.

A questão é que toda essa produção acaba gerando um grande acúmulo de lixo, que polui o meio ambiente, além de gerar desperdício, pois muitos produtos são adquiridos sem haver uma real necessidade de uso (BAUMAN, 2008). Além disso, gera ainda problemas de ordem psicológica e desgaste físico, já que para a maioria da população se manter consumindo, é necessário muito trabalho. Entretanto, mesmo trabalhando, nem todos possuem condições financeiras de se manter nessa sociedade de consumo, pois a maioria dos salários dos estudantes que trabalham e de seus familiares é baixa e insuficiente até mesmo para garantir as necessidades básicas, conforme aponta a pesquisa do Departamento Intersindical de Estatística e Estudos Socioeconômicos (DIEESE) de outubro de 2020. O salário-mínimo nacional em 2020 no Brasil é de $\mathrm{R} \$ 1.054,00$, porém de acordo com essa entidade, o salário-mínimo necessário para se sobreviver garantindo o básico seria de $\mathrm{R} \$ 5.005,91$.

Para se manter nessa sociedade, muitos se submetem a trabalhar de forma exaustiva, a fim de conquistar mais dinheiro para consumir produtos que são considerados supérfluos, mas que garantem um falso status nessa sociedade do consumo. Em casos extremos, há pessoas que entram em depressão ou até mesmo cometem suicídio por não poderem consumir determinados produtos e estarem participando de forma ativa como membros dessa sociedade de consumo, 0 que é altamente preocupante. É por isso que Bauman (2008) afirma que vivemos uma economia do engano, que aposta na irracionalidade dos consumidores, pois estimula as emoções consumistas, sem cultivar a razão.

Estes fatos nos levam a refletir a necessidade de uma Educação Financeira desde os 
anos iniciais da educação básica que não se restrinja ao ensino da Matemática Financeira e dos tipos de investimentos bancários. Para fazer frente ao modelo capitalista, é fundamental uma Educação Financeira na perspectiva crítica defendida por Kistemann Jr. (2011), que proporcione reflexões construtivas para os estudantes. Que o estudante não aprenda apenas a consumir, mas, sim, se deve consumir, e avalie os impactos pessoais e sociais do seu consumo.

\section{Metodologia de pesquisa}

Nesta seção abordamos a intervenção de ensino realizada com uma turma de 15 estudantes de um pré-vestibular social, na cidade de Duque de Caxias, a fim de descrever e analisar o processo de modelagem matemática favorecido pela reflexão coletiva de questões relacionadas à Educação Financeira.

A técnica de pesquisa que melhor se ajustou aos propósitos do nosso estudo e ao papel que desempenhávamos no campo — um de nós era o professor de Matemática da turma — foi a pesquisa-ação.

A pesquisa-ação é um tipo de pesquisa qualitativa em Educação e, de acordo com Fiorentini (2019) e Thiollent (1986), nela, o pesquisador se insere no ambiente a ser estudado para observá-lo e compreendê-lo, a fim de transformá-lo em direções que permitam a melhoria das práticas e a maior liberdade de ação e de aprendizagem dos participantes. Thiollent (1986) define pesquisa-ação como

um tipo de pesquisa social com base empírica que é concebida e realizada em estrita associação com uma ação ou com a resolução de um problema coletivo e no qual os pesquisadores e os participantes representativos da situação ou do problema estão envolvidos de modo cooperativo ou participativo. (p. 14).

Assim, é importante que todos os participantes estejam engajados na solução do problema ou na implementação da ação. Como a pesquisa-ação ocorre em cenários sociais não manipulados, suas variáveis não podem ser controladas, tendo um caráter mais intervencionista do que estritamente experimental. Para que se possa avançar nesse tipo de pesquisa, é necessário haver uma constante reflexão e ação, de forma que a solução dos problemas começam com a identificação do problema, o planejamento de uma solução, sua implementação, seu monitoramento e a avaliação de sua eficácia, como num ciclo contínuo, que pode ser representado pela Figura 1. 


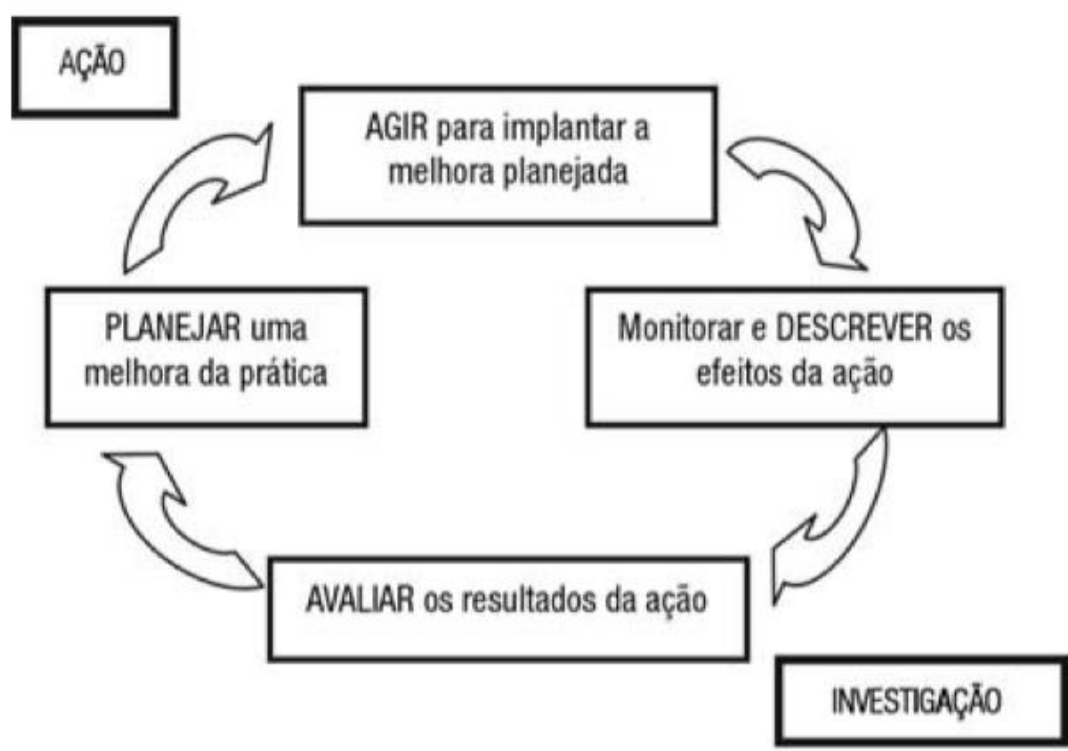

Figura 1: Ciclo de investigação e ação (TRIPP, 2005, p. 446)

Como mostrado na Figura 1, a cada ação é preciso refletir sobre os resultados, para que se possa fazer um novo planejamento. Fiorentini (2019) destaca que a pesquisa-ação é "uma modalidade de pesquisa que torna o participante da ação um pesquisador de sua própria prática, e o pesquisador, um participante que intervém nos rumos da ação, orientado pela pesquisa que realiza" (p. 77). Em nossa pesquisa, esse ciclo se iniciou quando identificamos os anseios dos estudantes pela Educação Financeira e a necessidade de se aprofundar os conhecimentos matemáticos para a realização das provas do vestibular. A implementação da intervenção foi a nossa ação e, por meio da observação da participação dos estudantes nas atividades, monitoramos, descrevemos seus efeitos e avaliamos seus resultados.

Destacamos, ainda, que, dentro da pesquisa-ação, podemos classificar esta pesquisa como socialmente crítica, pois trabalhamos para mudar ou contornar as limitações, buscando tornar o espaço de investigação num lugar melhor em termos de justiça social, promovendo a valorização dos indivíduos, a igualdade e compreensão, a cooperação, melhor atendimento às necessidades pessoais, entre outros. Tripp (2005) destaca que "a pesquisa-ação socialmente crítica passa a existir quando se acredita que o modo de ver e agir "dominante" do sistema, dado como certo relativamente a tais coisas, é realmente injusto de várias maneiras e precisa ser mudado" (p. 458).

O Pré-Vestibular Social para Negros e Carentes da Pastoral da Juventude é um curso que busca preparar estudantes negros e de baixa renda para ingressarem nas principais universidades públicas. O curso funciona nas dependências da Catedral Diocesana de Santo Antônio, uma 
importante igreja católica do município de Duque de Caxias.

Segundo os coordenadores, o curso nasceu do encontro de três linhas ideológicas fundamentais: o Materialismo Histórico e Dialético1, o Movimento Negro² e a Teologia da Libertação ${ }^{3}$. O pré-vestibular tem um compromisso ético e social, pois busca diminuir as desigualdades sociais, oferecendo condições para que indivíduos marginalizados pela sociedade possam pleitear por vagas em universidades públicas, concorrendo com estudantes da rede privada. Além disso, é um trabalho militante, que busca fortalecer aspectos de cidadania. Nossa pesquisa foi pensada no sentido de colocar as aulas de Matemática a serviço dessas causas. Vislumbramos nela uma oportunidade de o professor de Matemática ocupar um espaço que geralmente não é ocupado por professores das disciplinas de Ciências Exatas, mostrando ser possível realizar um ensino de Matemática que traga um olhar mais sensível para as questões sociais e a formação dos indivíduos enquanto cidadãos.

Como mencionamos anteriormente, os sujeitos da pesquisa são os 15 estudantes que cursam o pré-vestibular social da Pastoral da Juventude, em Duque de Caxias, e que estavam presentes nos dois dias em que realizamos a intervenção. Desses, 11 já haviam concluído a educação básica, enquanto outros 4 ainda estavam cursando $03^{\circ}$ ano do Ensino Médio.

Os estudantes são todos moradores da cidade de Duque de Caxias, residentes em favelas que existem nas proximidades do curso, oriundos de famílias de baixa renda e, em sua maioria, negros. Para complementar a renda familiar, 12 dos estudantes exercem algum tipo de atividade remunerada, ainda que informal, e outros 3 já são chefes de família.

Optamos por colocar em prática uma intervenção de ensino, composta por três atividades, realizadas em dois encontros de cerca duas horas cada um. Esses encontros foram gravados e as gravações, transcritas. Fizemos, ainda, um diário de bordo e recolhemos os registros produzidos pelos estudantes. Cabe mencionar que, em todas as atividades, os estudantes estavam divididos em um trio e três grupos com quatro componentes. As atividades foram Consumo x finanças e Orçamento doméstico, vivenciadas no primeiro encontro, e 0 poder dos

\footnotetext{
${ }^{1}$ Segundo Alves (2010), o Materialismo histórico e dialético pretende ser, ao mesmo tempo, o fim da filosofia e o início de uma nova filosofia, que não se limita a pensar o mundo, mas pretende transformá-lo.

2 "O Movimento negro é a luta dos negros na perspectiva de resolver seus problemas na sociedade abrangente, em particular os provenientes dos preconceitos e das discriminações raciais, que os marginalizam no mercado de trabalho, no sistema educacional, político, social e cultural." (DOMINGUES, 2007, p. 100).

3 De acordo com Noronha (2012), a Teologia da Libertação nasceu na Igreja Católica, como resposta das contradições existentes na América Latina, entre a pobreza extrema e a fé cristã de sua população. Assim, ela rompe com os conceitos tradicionais da Igreja, introduzindo ideias de igualdade social e direitos humanos.
} 
juros compostos, vivenciada no segundo encontro. Passamos a seguir à uma descrição mais detalhada delas.

\section{- Consumo x finanças}

Objetivos - a) Identificar problemas relacionados a consumo e a finanças enfrentados pelos estudantes e seus familiares; b) Reconhecer que a organização das finanças passa pela efetuação de cálculos, mas também pela revisão dos hábitos de consumo.

Procedimentos - Apresentando os dados sobre o percentual de famílias brasileiras endividadas - da Confederação Nacional do Comércio ${ }^{4}$ - escrevemos no quadro a questão 0 que leva os individuos a se endividarem? e propusemos que os grupos tentassem respondê-la para, na sequência, exporem suas respostas à turma.

Para refletir durante a atividade - Enquanto cada grupo expunha suas respostas, procurávamos destacar nas falas dos estudantes aspectos que reforçam algumas ideias de Bauman (2008): (i) o indivíduo como mercadoria, (ii) o consumo atrelado à felicidade, (iii) a diferença entre consumo e consumismo, (iv) o papel da mídia, (iv) a naturalização do consumo e (v) as consequências que um consumo irracional pode trazer.

\section{O orçamento doméstico}

Objetivos - a) Construir uma situação-problema que traduza em linhas gerais os problemas de orçamento doméstico enfrentados pelas famílias brasileiras de baixa renda; $b$ ) Identificar um modelo para distribuição da renda mensal entre as despesas; $c$ ) Reconhecer alguns princípios básicos na gestão dos recursos financeiros.

Procedimentos - Embora os estudantes tenham participado ativamente das reflexões propostas na atividade anterior, foi possível perceber que o anseio por discutir sobre os problemas financeiros que passavam estava acompanhado por um sentimento de constrangimento e vergonha para expor mais detalhadamente suas finanças. Assim, decidimos por construir coletivamente uma situação hipotética com dados e questão a ser respondida sugeridos pelos estudantes. Em linhas gerais, a situação consistiu em, conhecendo a renda e as despesas de uma família, os estudantes exercerem o papel de consultores financeiros para ajudá-la a "sair do vermelho". Após a construção da situação, cada grupo organizou uma nova planilha das despesas familiares e apresentou à turma. A comparação entre as planilhas permitiu a construção de um

\footnotetext{
${ }^{4}$ Disponivel em http://www.cnc.org.br/editorias/economia/pesquisas/pesquisa-de-endividamento-e-inadimplencia-do-
} consumidor-peic-julho. 
modelo para a distribuição da renda mensal entre as despesas.

Para refletir durante a atividade - Devemos estabelecer prioridades e controlar os impulsos consumistas, sabendo definir o que realmente é necessário e o que é supérfluo ou pode ser deixado para outro momento. Algumas despesas são essenciais e não podem ser cortadas, pois garantem as necessidades básicas. Além disso, é imprescindível não gastar tudo o que se ganha, para que se possa formar uma reserva de capital que poderá ser utilizada numa eventual emergência financeira, para realizar um sonho a longo prazo ou até mesmo garantir uma melhor qualidade de vida no futuro.

- O poder dos juros compostos

Objetivos - a) conceituar juros; b) encontrar um modelo matemático para o cálculo dos juros simples e dos juros compostos; c) analisar as taxas de juros dos bancos nas situações em que 0 indivíduo deixa de honrar o pagamento de uma fatura do cartão de crédito ou utiliza 0 dinheiro do cheque especial.

Procedimentos - Inicialmente discutimos sobre o que são os juros e a distinção entre juros simples e juros compostos. Dando continuidade, pedimos aos grupos que, com o auxílio de uma calculadora, identificassem o montante mensal durante um ano de uma dívida contraída a partir de um empréstimo de 100 reais à taxa de juros de 10\% ao mês. Como não especificamos o tipo de juros, eles deveriam considerar as duas possibilidades (simples e compostos). Com a análise coletiva desses dados, os estudantes chegaram aos modelos matemáticos para o cálculo de ambos os tipos de juros. Após esse momento, realizamos uma rápida busca na internet a fim de encontrar as taxas de juros cobradas pelas instituições financeiras no caso de não pagamento da fatura do cartão de crédito ou de utilização do cheque especial, que são as principais causas de endividamento, segundo dados da Confederação Nacional do Comércio. A partir das taxas encontradas, pedimos para cada grupo aplicar sobre uma dívida de 100 reais a taxa encontrada em diferentes períodos de tempo, a fim de analisar a evolução da dívida. Para facilitar os cálculos, sugerimos a utilização também da calculadora e da planilha eletrônica.

Para refletir durante a atividade - Os juros compostos possuem poder para aumentar exponencialmente uma dívida ou um investimento. As taxas de juros cobradas pelos bancos são sempre bastante elevadas, principalmente se comparadas às que costumam pagar quando efetuamos algum investimento.

Nas próximas seções, fazemos a análise dos dados coletados nas três atividades. Para 
efeitos de organização, a análise ela está estruturada por atividade.

\section{Consumo $x$ finanças}

A proposta de responder a questão 0 que leva os indivíduos a se endividarem? despertou o interesse dos estudantes. As reflexões ocorriam dentro dos grupos tendo por base experiências passadas dos estudantes, isto é, todos contavam momentos em que eles ou indivíduos que lhes são próximos estiveram endividados. Relatavam também o que fizeram para quitar as dívidas, mas, quando questionados por nós ou por colegas de turma sobre dívidas atuais, a maioria dos estudantes se desviava do assunto de modo que nenhum deles falou de sua situação financeira no mês da pesquisa e não pudemos ter certeza se alguém dali ainda estava endividado.

Inicialmente as respostas produzidas pelos grupos atribuíram o endividamento ao fato de os indivíduos gastarem mais do que recebem, porém, conforme os grupos interagiam, novas questões foram surgindo, como: Por que muitas pessoas acabam gastando mais do que recebem? É possível evitar que isso aconteça?

Fatos inesperados como problemas de saúde na família ou um conserto emergencial na residência, foram respostas para a primeira questão. Outras respostas foram na direção do consumo exagerado e tivemos a oportunidade de iniciar a reflexão sobre o papel do consumo na sociedade capitalista (BAUMAN, 2008), que perpassou toda a intervenção.

Entre as ações sugeridas pelos grupos para evitar o endividamento foi consensual a organização e o planejamento do orçamento familiar. Nas palavras de um estudante: "Tem gente que compra o que não precisa sem saber nem se pode pagar. Tem que saber quanto ganha, quanto precisa gastar, quanto pode gastar, quanto pode juntar!". Assim, os estudantes reconheciam que é necessário organizar as finanças, inclusive por escrito, separando e até mesmo hierarquizando despesas.

\section{0 orçamento doméstico}

A participação dos estudantes na atividade anterior nos deu indícios de que deveríamos dar continuidade à intervenção. No entanto, era necessário um ajuste, o que não nos surpreendeu uma vez que realizávamos uma pesquisa-ação. Seguindo os princípios da modelagem matemática que apresentamos anteriormente, mais especificamente as ideias de Borba, Meneghetti e Hermini 
(1997), nessa atividade pretendíamos propor que os grupos escolhessem o orçamento familiar de um de seus componentes para trabalhar e oferecer a consultoria financeira. Porém, percebemos que a temática financeira que tanto motivava os estudantes também os constrangia, caso precisassem expor suas despesas, seus ganhos e suas dívidas para os colegas. Assim, substituímos a proposta inicial pela construção coletiva de uma situação-problema que, na sequência, foi discutida por cada grupo. A situação-problema construída em parceria com os estudantes foi:

Rafael e Lúcia são casados e estão passando por problemas financeiros, pois todos os meses têm faltado dinheiro para cobrir as despesas, tendo que recorrer com frequência ao uso do cartão de crédito para adiar os pagamentos. Eles moram de aluguel numa casa com um filho de 10 anos. Juntos, acumularam uma divida no cartão de crédito, que após muita negociação, foi refinanciada em 48 prestações mensais de 100 reais. Como podemos ajudá-los a conseguir honrar com todas as prestações, evitando que 0 problema se agrave? Rafael recebe $R \$ 1000,00$ de salário e Lúcia $R \$ 1200,00$.

Ainda que esse problema não seja propriamente de nenhum estudante, tendo em vista a participação da turma na sua elaboração e a análise que fizemos do questionário socioeconômico que os estudantes responderam no ato da matrícula do curso, podemos inferir que ele se aproxima dos problemas financeiros vividos por eles e seus familiares. Evidências disso estão nos valores que definiram para os salários dos personagens e os itens que escolheram para elencar na planilha de despesas que compõem o orçamento da família apresentado na Tabela 1:

Tabela 1: Ficha de registro da atividade sobre o orçamento doméstico

\begin{tabular}{|c|c|c|}
\hline \multicolumn{3}{|c|}{ Despesas } \\
\hline & Antes & Depois \\
\hline Aluguel & $\mathrm{R} \$ 500,00$ & \\
\hline Alimentação & $\mathrm{R} \$ 450,00$ & \\
\hline Luz & $\mathrm{R} \$ 150,00$ & \\
\hline Água & $\mathrm{R} \$ 60,00$ & \\
\hline Internet & $\mathrm{R} \$ 110,00$ & \\
\hline Celular & $\mathrm{R} \$ 100,00$ & \\
\hline Escola & $\mathrm{R} \$ 150,00$ & \\
\hline Transporte & $\mathrm{R} \$ 200,00$ & \\
\hline
\end{tabular}




\begin{tabular}{|c|c|c|}
\hline Cuidados pessoais & $\mathrm{R} \$ 300,00$ & \\
\hline Gás & $\mathrm{R} \$ 60,00$ & \\
\hline Passeios & $\mathrm{R} \$ 300,00$ & \\
\hline Farmácia & $\mathrm{R} \$ 150,00$ & \\
\hline Vestuário & $\mathrm{R} \$ 150,00$ & \\
\hline Financiamento da dívida & ----- & $\mathrm{R} \$ 100,00$ \\
\hline Total & & \\
\hline
\end{tabular}

Fonte: Araújo (2020, p. 4, com adaptação)

Vale destacar que também não estava no nosso planejamento a composição dessa planilha, entretanto essa foi uma sugestão de quase todos os estudantes, que traziam da atividade anterior as reflexões sobre a importância da organização dos gastos e da utilização de uma planilha como instrumento para isso.

Depois de discutirem a situação, os grupos, então, apresentaram suas planilhas para a turma, com a coluna do depois preenchida, isto é, com os novos valores que a consultoria havia definido como adequados para cada categoria. Na Tabela 2 apresentamos a planilha produzida por um dos grupos.

Tabela 2: Ficha de registro da atividade sobre o orçamento doméstico preenchida

\begin{tabular}{|c|c|c|}
\hline Categoria & Antes & Depois \\
\hline Aluguel & $\mathrm{R} \$ 500,00$ & $\mathrm{R} \$ 500,00$ \\
\hline Alimentação & $\mathrm{R} \$ 450,00$ & $\mathrm{R} \$ 450,00$ \\
\hline Luz & $\mathrm{R} \$ 150,00$ & $\mathrm{R} \$ 90,00$ \\
\hline Água & $\mathrm{R} \$ 60,00$ & $\mathrm{R} \$ 60,00$ \\
\hline Internet & $\mathrm{R} \$ 110,00$ & $\mathrm{R} \$ 60,00$ \\
\hline Celular & $\mathrm{R} \$ 100,00$ & $\mathrm{R} \$ 40,00$ \\
\hline Escola & $\mathrm{R} \$ 150,00$ & --- \\
\hline Transporte & $\mathrm{R} \$ 200,00$ & $\mathrm{R} \$ 100,00$ \\
\hline Cuidados pessoais & $\mathrm{R} \$ 300,00$ & $\mathrm{R} \$ 150,00$ \\
\hline
\end{tabular}




\begin{tabular}{|c|c|c|}
\hline Gás & $\mathrm{R} \$ 60,00$ & $\mathrm{R} \$ 60,00$ \\
\hline Passeios & $\mathrm{R} \$ 300,00$ & $\mathrm{R} \$ 50,00$ \\
\hline Farmácia & $\mathrm{R} \$ 150,00$ & -- \\
\hline Vestuário & $\mathrm{R} \$ 150,00$ & $\mathrm{R} \$ 100,00$ \\
\hline Dívida de renegociação & & $\mathrm{R} \$ 100,00$ \\
\hline Total & $\mathrm{R} \$ 2.680,00$ & $\mathrm{R} \$ 1760,00$ \\
\hline
\end{tabular}

Fonte: Araújo (2020, p. 4, com adaptação)

A comparação das planilhas produzidas pelos quatro grupos fez com que os estudantes reconhecessem que haviam estabelecido novos valores muito semelhantes para cada categoria, por exemplo, para o aluguel, dois grupos estabeleceram 500 reais, um grupo estabeleceu 450 reais e outro estabeleceu 550 reais. As reflexões sobre tais semelhanças os conduziram a tentar criar com base na realidade em que estão inseridos um modelo que definisse um percentual dos ganhos familiares a ser destinado para algumas categorias. Assim, definiram que, para o aluguel, uma família deve destinar entre $20 \%$ e $30 \%$ de seus ganhos e repetiram esse intervalo para o caso da alimentação. Entendemos que a exploração dos dados, a observação dos padrões e a definição dos percentuais pelos estudantes são elementos de um processo de modelagem matemática e as análises críticas que eles fizeram com base na situação nos indicaram o papel sociocultural da matemática (BLUM, 1995).

Nessa atividade, os estudantes puderam explorar os dados que eles mesmos trouxeram e verificar padrões na distribuição dos valores pelas categorias, o que lhes permitiu concluir que todos ali presentes ou seus familiares exerciam um ofício que possuía baixa remuneração, embora trabalhassem muito. Essa constatação, por sua vez, desencadeou uma sucessão de falas contrárias à má distribuição da renda e às desigualdades sociais brasileiras, como pode ser verificado nas palavras de um estudante: "Aqui no Brasil é muito engraçado, quem trabalha mais é quem ganha menos. Isso tem que mudar. O povo tem que saber escolher os governantes". Com base em suas explorações e cálculos, os estudantes puderam concluir que uma despesa que pesa nos custos de uma família das classes mais populares é o pagamento do aluguel, que, mesmo quando ela opta por uma habitação com custo mais acessível, isto corresponde a aproximadamente $50 \%$ do salário-mínimo. Além de tudo, é uma despesa essencial, que não pode ser eliminada, assim como a alimentação. 
Em relação aos gastos com farmácia, houve um estudante que sugeriu sua retirada do orçamento, pois segundo ele, "filho de pobre não pode ficar doente". Essa fala nos faz refletir sobre a dificuldade encontrada por esses sujeitos para lidar com o tratamento de doenças, tendo que arcar com custos de medicações que não são acessíveis. De acordo com Bauman (2008), o capitalismo preconiza as desigualdades socais, que são fundamentais para a manutenção desse sistema. A partir do momento em que o estudante percebe sua condição de dificuldade, temos um ponto de partida para uma Educação Financeira crítica, como sugere Kistemann Jr. (2011).

Quanto à educação, foi unanimidade que o filho do casal hipotético da situação analisada deveria estudar em escola pública. Em suas falas, os estudantes constatavam que as famílias que vivem nas periferias necessitam dos serviços públicos para que possam se manter, pois os salários que recebem são insuficientes. Voltando as reflexões para as questões políticas locais, os estudantes comentaram também que é importante que o governo não só mantenha os atuais serviços de assistência à população, mas que os amplie, investindo mais em educação, saúde, programas de habitação social, espaços públicos para lazer etc., numa tentativa de amenizar as desigualdades sociais e possibilitar uma melhor qualidade de vida à população.

\section{0 poder dos juros compostos}

Iniciamos essa atividade com a reflexão sobre juros e a distinção entre juros simples e juros compostos. Nesses momentos iniciais, chamou a nossa atenção a descoberta de alguns estudantes de que também é possível ganhar dinheiro com os juros. Para eles, a palavra juros tinha um significado tão negativo, associado apenas a dívidas, que sequer admitiam a possibilidade de investir dinheiro e receber juros por isso.

Para a compreensão da distinção entre juros simples e juros compostos, depois de uma breve explicação, cada grupo, com o auxílio de uma calculadora, tomando como exemplo um investimento de 100 reais a uma taxa de juros de $10 \%$ ao mês preencheu uma tabela como a Tabela 3 que segue.

Tabela 3: Tabela comparativa de juros simples e juros compostos

\begin{tabular}{|c|c|c|}
\hline \multirow{2}{*}{ Tempo (meses) } & \multicolumn{2}{|c|}{ Montante } \\
\cline { 2 - 3 } & Juros simples & Juros compostos \\
\hline 1 & $\mathrm{R} \$ 110,00$ & $\mathrm{R} \$ 110,00$ \\
\hline
\end{tabular}




\begin{tabular}{|c|c|c|}
\hline 2 & $\mathrm{R} \$ 120,00$ & $\mathrm{R} \$ 121,00$ \\
\hline 3 & $\mathrm{R} \$ 130,00$ & $\mathrm{R} \$ 133,10$ \\
\hline 4 & $\mathrm{R} \$ 140,00$ & $\mathrm{R} \$ 146,41$ \\
\hline 5 & $\mathrm{R} \$ 150,00$ & $\mathrm{R} \$ 161,05$ \\
\hline 6 & $\mathrm{R} \$ 160,00$ & $\mathrm{R} \$ 177,16$ \\
\hline 7 & $\mathrm{R} \$ 170,00$ & $\mathrm{R} \$ 194,87$ \\
\hline 8 & $\mathrm{R} \$ 180,00$ & $\mathrm{R} \$ 214,36$ \\
\hline 9 & $\mathrm{R} \$ 190,00$ & $\mathrm{R} \$ 235,79$ \\
\hline 10 & $\mathrm{R} \$ 200,00$ & $\mathrm{R} \$ 259,37$ \\
\hline 11 & $\mathrm{R} \$ 210,00$ & $\mathrm{R} \$ 285,31$ \\
\hline 12 & $\mathrm{R} \$ 220,00$ & $\mathrm{R} \$ 313,84$ \\
\hline
\end{tabular}

Fonte: Araújo (2020, p. 4, com adaptação)

Com os dados dessa Tabela 3 e com o auxílio do GeoGebra, construímos coletivamente o gráfico da Figura 2:

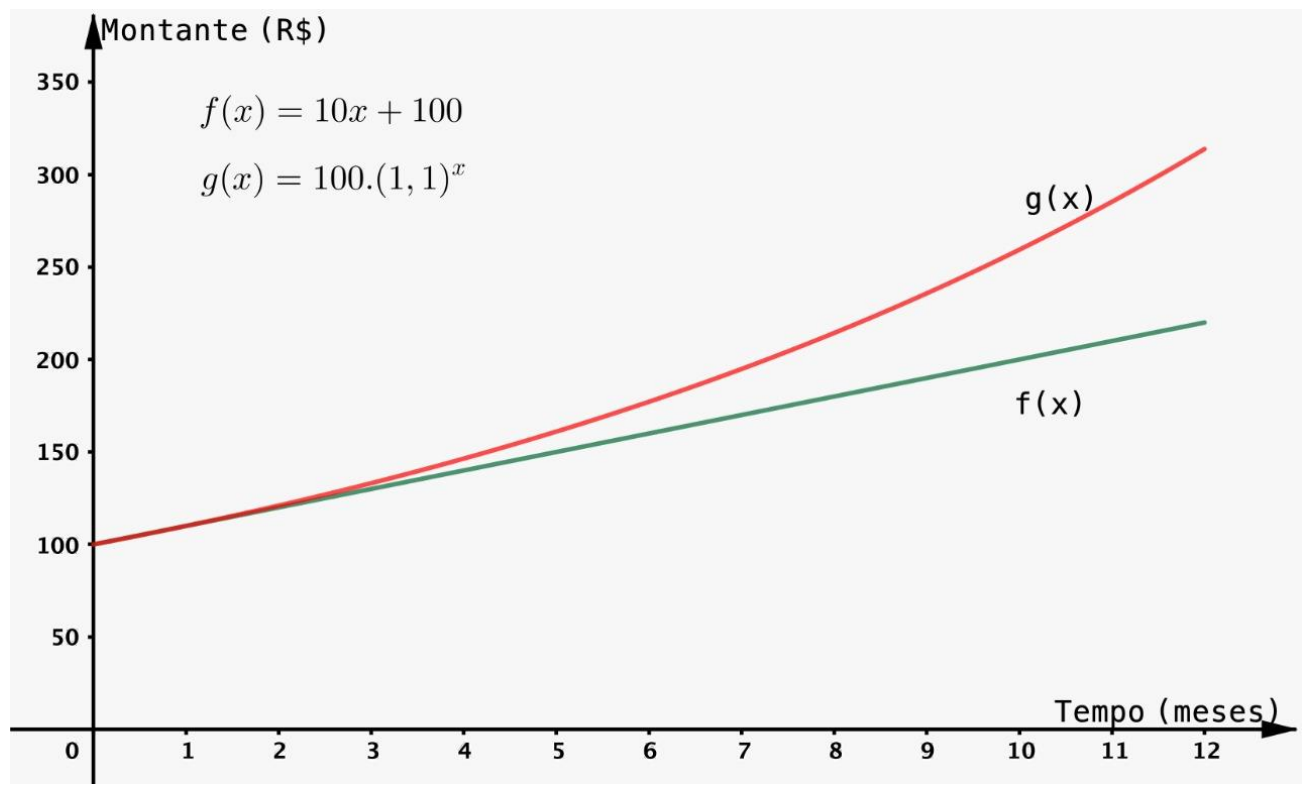

Figura 2: Gráfico comparativo entre juros simples e juros compostos (Dados da Pesquisa, 2020)

A observação dos dados da Tabela 3 e do gráfico (Figura 2) favoreceu a compreensão da distinção entre os juros simples e os juros compostos. Isso foi verificado em comentários dos estudantes como, "se os juros forem compostos, a dívida cresce mais rápido", ou ainda, "quanto 
mais a gente demora a pagar, maior vai ficando a diferença" e "na vida ninguém cobra juros simples, os bancos, o cartão de crédito cobram esse outro aí que a dívida cresce rapidinho".

Já a análise dos cálculos que realizaram para preencher a tabela conduziu os estudantes à produção de um modelo matemático para a obtenção do montante da dívida para cada tipo de juros em função do tempo $x$ de empréstimo, ou seja, $f(x)=100+10 x$, para os juros simples, e $g(x)=100(1,1)^{x}$, para os juros compostos. No entanto, é importante sinalizar que a vivência dessa situação não foi suficiente para uma generalização maior em que os estudantes escrevessem modelos para os montantes, sendo definidos como $\mathrm{C}$ o capital e i, a taxa de juros. Esse fato nos permitiu inferir sobre a importância da exploração de mais de uma situação e da comparação de situações para o processo de modelagem (BASSANEZI, 1994).

Na sequência, discutimos sobre as taxas que são cobradas pelos cartões de crédito em caso de atraso e pelo uso do cheque especial —crédito pré-aprovado, que fica à disposição na conta corrente. Para isso, analisamos faturas de cartões de créditos e extratos bancários, onde constam as taxas de juros que são praticadas. As taxas cobradas, em ambos os casos, foram as apresentadas na Figura 3.

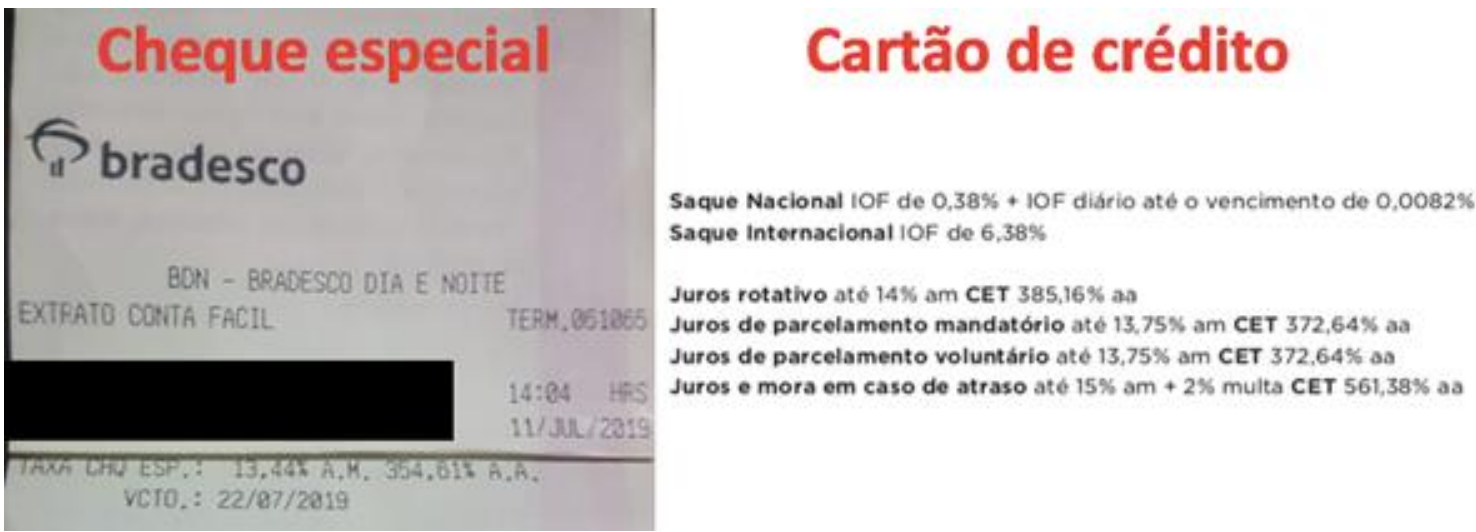

Figura 3:Taxas de juros do cartão de crédito e do cheque especial. (Dados da pesquisa, 2020)

Como as taxas de juros do cheque especial e do cartão de crédito eram bem próximas, optaram por fazer as projeções adotando apenas a taxa de $13,44 \%$ ao mês. Com o auxílio da tecnologia, os grupos fizeram projeções sobre a evolução de uma dívida de $R \$ 100,00$ utilizando a calculadora e planilha eletrônica.

Em um ano, puderam verificar que a dívida de $R \$ 100,00$ evoluiu para $R \$ 454,15$, passando a ser aproximadamente 4 vezes maior do valor inicial. Os estudantes, em sua maioria, afirmaram desconhecer que as taxas eram tão altas. Então, continuamos com os cálculos, fazendo projeções para 2, 3, 5, 10, 20 e 30 anos. 
Conforme iam fazendo as projeções, os estudantes concluíram que uma simples dívida de $R \$ 100,00$ se torna impagável em pouco tempo e puderam refletir sobre como é fácil se endividar. Entretanto, um estudante relatou que já passou por situações desse tipo e que escolheu pegar um empréstimo com taxas menores para pagar uma dívida do cartão de crédito. Alguns citaram ainda a possibilidade de pagar a fatura do cartão de crédito com outro cartão de crédito, por meio de aplicativos de pagamentos existentes no celular. Assim, é possível postergar os pagamentos para o próximo mês, sem precisar pagar juros. Em meio à discussão, no entanto, um estudante alertou para o fato de que, apesar de ser um caminho alternativo para não se pagar os juros, essa prática não deve ser recorrente, pois, ao adiar o pagamento de uma dívida, o indivíduo terá que pagar a fatura de dois meses no mês seguinte.

Observando a participação de cada estudante nos debates, verificamos que essa atividade foi um mote para se discutir sobre o uso do cartão, o que ele representa socialmente e se são valores de uma educação financeira saudável. De acordo com Bauman (2008), vivemos numa sociedade movida pelo status e pela ostentação. Portar um cartão de crédito, muitas vezes, é visto como um sinônimo de prosperidade e status social, sendo, portanto, desejado por muitos. Kistemann Jr. (2011) nos alerta para o fato de que alguns indivíduos, quanto mais possuem, mais querem gastar. Nesse caso, o limite disponível no cartão pode ser uma armadilha, pois esconde riscos que podem comprometer o bem estar financeiro, se não for utilizado com prudência. Temos, assim, mais uma vez, a modelagem colocando a matemática a serviço das questões sociais, dos questionamentos da ordem capitalista e das desigualdades impostas por esse sistema.

\section{Considerações finais}

Nessa pesquisa tivemos o objetivo de descrever e analisar o processo de modelagem vivenciado pelos estudantes e suas potencialidades críticas. Como mencionado anteriormente, colocamos em prática uma intervenção de ensino composta por três atividades numa turma de 15 estudantes de um curso pré-vestibular social voltado jovens e adultos negros e pertencentes a famílias de baixa renda.

Os resultados nos levam a concluir que a Educação Financeira é uma área que oferece circunstâncias para a modelagem em três vieses: 0 da construção de conceitos matemáticos específicos, 0 da construção de habilidades matemáticas gerais e o do entendimento do papel sociocultural da Matemática pelos estudantes. Entre os conceitos matemáticos que emergiram ao 
longo da intervenção, destacamos porcentagem, juros simples, juros compostos, função afim, função exponencial e gráficos de funções. É importante explicar que esses conceitos emergiram ao longo dos diálogos ocorridos no contexto das atividades, ou melhor, na vivência das situaçõesproblema propostas pelo grupo. Não é nossa pretensão afirmar que os processos de aprendizagem dos estudantes tiveram início e fim na intervenção. No caso da porcentagem, todos mostraram dominar tal conceito ao usá-lo na construção dos orçamentos e no cálculo dos juros.

A distinção entre juros simples e juros compostos foi, de fato, um ganho para os estudantes, o que mostramos ao longo do artigo nos comentários feitos por eles, embora ainda fosse necessário explorar tais conceitos em outros contextos para que os estudantes fossem capazes de generalizações mais abrangentes. Já conceitos associados a funções afins e exponenciais foram também vivenciados na análise das situações, sem que houvesse formalizações ou uso da nomenclatura, o que nos permitiu inferir que a intervenção que propomos permite a introdução desses temas junto aos estudantes, sendo fundamental a realização de novas intervenções para que os eles avançassem na construção de tais conceitos.

Entre as habilidades matemáticas gerais, ou seja, entre as habilidades necessárias para que os indivíduos produzam saberes matemáticos se enleva a de observar e explorar uma situação-problema, percebendo a existência ou inexistência de padrões. Já as reflexões sobre consumo, sobre o incentivo dos bancos ao uso do cartão de crédito, sobre as altas taxas para os empréstimos bancários, para o cheque especial e para o cartão de crédito, sobre a necessidade do poder público assegurar serviços de saúde e educação de qualidade para a população de baixa renda permitiram o desenvolvimento de uma postura crítica no que concerne ao consumismo e às desigualdades sociais brasileiras, mostrando, assim, o papel sociocultural da matemática.

É evidente que nossos dados não podem ser generalizados, mas acreditamos que eles enriquecem as discussões sobre modelagem matemática e Educação Financeira, sinalizando possibilidades de aproximação entre as duas áreas e o desenvolvimento do espírito crítico dos estudantes como consequência dessa aproximação. Entre as potencialidades da Educação Financeira para a modelagem matemática, podemos destacar inicialmente a relevância do tema para a maioria dos estudantes brasileiros, o que pode despertar seus interesses por problematizar situações reais ligadas a ele, o que é o ponto de partida para a modelagem. Além disso, as discussões suscitadas pela Educação Financeira recaem em conceitos matemáticos distintos, permitindo que os estudantes observem pontos de aproximação entre eles. 


\section{Referências}

ALLEVATO, Norma Suely Gomes. ONUCHIC, Lourdes de la Rosa. Ensinando Matemática na sala de aula através da Resolução de Problemas. Boletim GEPEM, Rio de Janeiro, n. 55, p. 133-154, jul./dez. 2009.

ALVES, Alvaro Marcel. O método materialista histórico dialético: alguns apontamentos sobre a subjetividade. Revista de Psicologia da UNESP, Assis, v. 9, n. 1, p. 1-13, jan./jun. 2010.

ANDREATTA, Cidimar; ALLEVATO, Norma Suely Gomes. Aprendizagem matemática através da elaboração de problemas em uma escola comunitária rural. Educação Matemática Debate, Montes Claros, v. 4, n. 10, p. 1-23, 2020.

ARAÚJJO, Jerlan Manaia de. Educação Financeira: concepções de estudantes de um prévestibular social em Duque de Caxias. 2020. 136f. Dissertação (Mestrado em Educação, Cultura e Comunicação) - Faculdade de Educação da Baixada Fluminense. Universidade do Estado do Rio de Janeiro. Duque de Caxias.

ARAÚJJO, Jussara de Loiola. Cálculo, Tecnologias e Modelagem Matemática: as discussões dos alunos. 2002. Tese (Doutorado em Educação Matemática) — Instituto de Geociências e Ciências Exatas. Universidade Estadual Paulista. Rio Claro.

ARAÚJO, Jussara de Loiola. Relação entre Matemática e realidade em algumas perspectivas de modelagem matemática na Educação Matemática. In: BARBOSA, Jonei Cerqueira; CALDEIRA, Ademir Donizete; ARAÚJO, Jussara de Loiola. (Org.). Modelagem Matemática na Educação Matemática Brasileira: pesquisas e práticas educacionais. Recife: SBEM, 2007, p. 17-32.

BARBOSA, Gabriela dos Santos. O Teorema Fundamental da Aritmética: jogos e problemas com alunos do sexto ano do Ensino Fundamental. 2008. 308f. Tese (Doutorado em Educação Matemática) - Faculdade de Ciências Exatas e Tecnologias. Pontifícia Universidade Católica de São Paulo. São Paulo.

BASSANEZI, Rodney Carlos. Ensino-aprendizagem com modelagem matemática: uma nova estratégia. São Paulo: Contexto, 2002.

BASSANEZI, Rodney Carlos. Modelagem matemática. Dynamis, Blumenau, v. 2, n. 7, p. 55-80, 1994.

BAUMAN, Zygmunt. Vida para consumo: a transformação das pessoas em mercadorias. Tradução de Carlos Alberto. Medeiros. Rio de Janeiro: Zahar, 2008.

BLUM, Werner. Applications and modelling in mathematics teaching and Mathematics Education: some important aspects of practice and of research. In: SLOYER, Cliff; BLUM, Werner; HUNTLEY, lan. (Ed.) Advances and perspectives in the teaching of Mathematical Modelling and applications. Yorklyn: Water Street Mathematics, 1995, p. 1-20.

BORBA, Marcelo de Carvalho; MENEGHETTI, Renata Cristina Geromel; HERMINI, Helba Alexandre. Modelagem, calculadora gráfica e interdisciplinaridade na sala de aula de um curso de Ciências Biológicas. Revista de Educação Matemática, São José do Rio Preto, v. 5, n. 3, p. 63-70, 1997. 
CHEVALLARD, Yves; BOSCH, Marianna; GASCÓN, Josep. Estudar Matemáticas: o elo perdido entre o ensino e a aprendizagem. Tradução de Dayse Vaz de Moraes. Porto Alegre: Artmed, 2001.

DOMINGUES, Petrônio. Movimento negro brasileiro: alguns apontamentos históricos. Tempo, Niterói, v. 12, n. 23, p. 100-122. 2007.

FIORENTINI, Dario. Pesquisar práticas colaborativas ou pesquisar colaborativamente?. In: BORBA, Marcelo de Carvalho; ARAÚJO, Jussara de Loiola. (Org.). Pesquisa Qualitativa em Educação Matemática. 6 ed. Belo Horizonte: Autêntica, 2019, p. 53-83.

GALBRAITH, Peter; CLATWORTHY, Neville. Beyond standard models: meeting thechallenge of Modelling. Educational Studies in Mathematics, v. 21, n. 2, p. 137-163, apr. 1990.

GOMES; Maristela Gonçalves. Solução de problemas de Matemática: procedimentos utilizados por sujeitos com graus de escolaridade diferentes. 1998. 170f. Dissertação (Mestrado em Educação) — Faculdade de Educação. Universidade Estadual de Campinas. Campinas.

KISTEMANN JR., Marco Aurélio. Sobre a produção de significados e a tomada de decisão de indivíduos-consumidores. 211. 540f. Tese (Doutorado em Educação Matemática) - Instituto de Geociências e Ciências Exatas. Universidade Estadual Paulista. São Paulo.

KISTEMANN JR., Marco Aurélio; LINS, Romulo Campos. Enquanto isso na sociedade de consumo líquido-moderna: a produção de significados e a tomada de decisão de indivíduos consumidores. Bolema, Rio Claro, v. 28, n. 50, p. 1303-1326, dez. 2014.

NACARATO, Adair Mendes; MENGALI, Brenda Leme da Silva; PASSOS, Carmen Lucia Brancaglion. A Matemática nos Anos Iniciais do Ensino Fundamental: tecendo fios do ensinar e do aprender. 2. ed. Belo Horizonte: Autêntica, 2015.

NORONHA, Cejana Uiara Assis. Teologia da libertação: origem e desenvolvimento. Fragmentos de Cultura, Goiânia, v. 22, n. 2, p. 185-191, abr./jun. 2012.

ONUCHIC, Lourdes de la Rosa. Ensino-aprendizagem de Matemática através da resolução de problemas. In: BICUDO, Maria Aparecida Viggiani. (Org.). Pesquisa em Educação Matemática: concepções e perspectivas. São Paulo: Editora UNESP, 1999, p. 199-220.

SAITO, André Taue. Uma contribuição ao desenvolvimento da educação em finanças pessoais no Brasil. 2007. 152f. Dissertação (Mestrado em Administração) - Faculdade de Economia, Administração e Contabilidade. Universidade de São Paulo. São Paulo.

SMOLE, Katia Stocco. A Matemática na Educação Infantil: a teoria das inteligências múltiplas na prática escolar. Porto Alegre: Artmed, 2003.

SMOLE, Katia Stocco; DINIZ, Maria Ignez; CÂNDIDO, Patricia Terezinha. Resolução de Problemas. Porto Alegre: Artmed, 2000.

SOUZA, Almir Ferreira.; TORRALVO, Caio Fragata. Aprenda a administrar o próprio dinheiro: coloque em prática o planejamento financeiro pessoal e viva com mais liberdade. São Paulo: Saraiva, 2008. 
THIOLLENT, Michel. Metodologia da pesquisa-ação. 2 ed. São Paulo: Cortez, 1986.

TRIPP, David. Pesquisa-ação: uma introdução metodológica. Educação e Pesquisa, São Paulo, v. 31. n. 3, p. 443-466, set./dez. 2005.

VAN DE WALLE, John A. Matemática no Ensino Fundamental: formação de professores e aplicação em sala de aula. Tradução de Paulo Henrique Colonese. 6 ed. Porto Alegre: Artmed, 2009. 